\title{
¿CÓMO CONFIGURAN LOS ESPAÑOLES SU VESTUARIO?
}

\author{
ANA MARTÍNEZ BARREIRO \\ Universidad de La Coruña \\ PALABRAS CLAVE ADICIONALES \\ Consumo, Moda, Ropa, Género. \\ ADDITIONAL KEYWORDS \\ Consumption, Fashion, Gender, Dress. \\ RESUMEN. El trabajo que aquí se presenta contiene dos partes bien diferenciadas. En primer \\ lugar, se analizan las principales aportaciones teóricas que se han producido sobre la moda desde \\ finales del siglo XIX hasta la actualidad, contribuyendo, así a contrastar e integrar teorías para \\ explicar el fenómeno de la moda. Y, en segundo lugar, se analiza el modo en que cada una de las \\ variables consideradas (sexo, edad, nivel de estudios...) ejerce una influencia causal sobre las \\ variaciones del vestuario de los españoles, quedando de manifiesto que el efecto renta o capital \\ humano, la edad o el ciclo de vida, el rol o segregación femenina, son sus principales causas.
}

Hoy como ayer seguimos preguntándonos si existen leyes capaces de explicar el cambio vestimentario. Mientras la sociología clásica se ha atrevido a formular alguna "ley general" o a descubrir algún factor predominante, la sociología moderna se ha fijado objetivos más modestos y quizá por este motivo haya conseguido mejores resultados. Entre las consideraciones que más inciden en los estudios de la sociología de la moda la más evidente es que ésta constituye un fenómeno típicamente contradictorio, en el sentido de que mientras su existencia pide la participación de un cierto número de personas, esa misma existencia se ve destruida sin embargo, cuando supera un cierto límite. De ahí que la moda se presente como uno de los fenómenos que mejor expresan la latente conflictividad entre las clases o fracciones de clase. Analizarla desde este punto de vista supo-

\section{Revista Internacional de Sociología (RIS)}

Tercera Época, $n^{\circ}$ 25, Enero-Abril, 2000, pp. 77-98. 
ne adentrarnos en los supuestos clásicos de la perspectiva de la estratificación de la moda desde Spencer a Simmel, y desde Veblen hasta las teorías modernas de Bourdieu y Baudrillard.

\section{MODA Y ESTRATIFICACIÓN: DE LAS TEORÍAS CLÁSICAS A LAS CONTEMPORÁNEAS}

Simmel, en un artículo publicado por primera vez en 1895 con el título " $\mathrm{La}$ Moda" en el que hace referencia a las afirmaciones de Spencer ', sitúa las raíces del fenómeno de la moda en dos tendencias antagónicas y que actúan unitariamente: la imitación o igualación social y la diferenciación individual o cambio. En este sentido: "la moda es imitación de un modelo dado y satisface la necesidad de apoyo social, ya que conduce al individuo por el camino que todos transitan y crea un modelo general que reduce la conducta de cada uno a mero ejemplo de una regla. Pero no menos, satisface la necesidad de distinguirse, la tendencia a cambiar y a destacar. Logra esto, por una parte, merced a la variación de sus contenidos, que presta cierta individualidad a la moda de hoy frente a la de ayer. Pero aún es más importante, en este sentido, el hecho de que siempre, las modas son modas de clase, de manera que la clase social superior se diferencia de la inferior, y las abandona en el momento en que esta última empieza a acceder a ellas" (Simmel, 1988: 28-29).

Veblen es el primer autor que señala explícitamente que los fenómenos de la moda dependen de la estructura social y no de las necesidades naturales. En su Teoría de la clase ociosa (Veblen, 1974: 174), explica cómo a través del gasto en materia vestimentaria, el individuo no sólo ha de mostrar que es capaz de consumir por un valor relativamente grande, sino que ha de indicar, a la vez, que consume sin producir. Esta argumentación le permite afirmar que la regla que mejor expresa el gasto del vestuario es el derroche-ostensible, ya que actúa como un principio regulador de la reputación pecuniaria, y tiene la ventaja de mostrar a primera vista, la capacidad económica del individuo. De ahí que la mayor parte del gasto realizado por todas las clases sociales en su atavío se realiza con el propósito de conseguir una apariencia respetable. Esto le lleva a decir que "la necesidad del vestido es una necesidad eminentemente espiritual o superior" (Ibídem: 174), ya que el valor de los materiales empleados en el vestido no está en su valor comercial, sino en el hecho de que esté de moda y en el aumento de la propia reputación. Estas consideraciones permiten afirmar que la nor-

\footnotetext{
'Antes que Spencer, Gabriel Tarde ya había hablado de un instinto humano de imitación, que consideraba el origen de todo fenómeno psíquico y social. Sin embargo, su teoría, aunque orgánica y sistemática, se desarrolla sobre un ámbito diferente del que aquí nos interesa.
} 
ma del derroche-ostensible ejerce una vigilancia reguladora en todo lo relativo al vestido, de tal modo que cualquier cambio de moda tiene que conformarse a dicha exigencia.

En la actualidad, la teoría de Veblen se ha convertido en un marco de referencia y ha adquirido un valor de modelo interpretativo para entender el consumo como una estructura de segregación y estratificación. Por su parte, Baudrillard afirma que nunca se consume un objeto por su valor de uso, sino en razón de su valor de cambio, es decir, en razón del prestigio o el estatus social que confiere. Así, lo que motiva a los consumidores no es el valor de uso de las mercancías, sino su aspiración al rango y la diferencia social, pues los objetos no son más que exponentes de clase que funcionan como signos de movilidad y aspiración social. De esta forma, la lógica del objeto-signo es la que impulsa a la renovación acelerada de los objetos bajo la reestructuración del imperio de la moda. Y, al mismo tiempo, las audaces y aberrantes novedades de la moda tienen como función volver a crear distancias, excluir a la mayoría incapaz de asimilarlas de inmediato y distinguir a las clases privilegiadas que sepan apropiárselas. Por consiguiente, "la función social de la innovación formal en materia estética es una función de discriminación cultural, ya que la innovación formal en materia de objetos no tiene como fin un mundo de objetos ideales, sino un ideal social, el de las clases privilegiadas, que intenta reactualizar perpetuamente su privilegio cultural" (Baudrillard, 1974: 28). Al mismo tiempo, contribuye a la inercia social, en cuanto que la renovación de los objetos permite compensar una ausencia de movilidad social real. En este sentido, la moda como instrumento de distinción de clases, reproduce la segregación social y cultural, y participa de las mitologías modernas que enmascaran una igualdad inexistente.

Otro punto obligado de reflexión teórica en las sociedades contemporáneas es la Teoría de la Distinción (Bourdieu, 1988) donde se ejemplifica el capital cultural como generador de estilos de vida diferenciados. Pierre Bourdieu, en lugar de crear un espacio social subjetivista, llega a construir el espacio social en un sentido objetivo, basándose en los tres componentes de la clase social: "capital económico", "capital cultural" y "capital social" (Ibidem, p. 169). Al mismo tiempo evoca que la posesión de ciertos bienes culturales atestiguan no sólo la riqueza de su propietario, sino también su buen gusto, como una garantía de legitimidad. Así, "de la misma forma que los bienes culturales están sutilmente jerarquizados para marcar los grados de progreso iniciático, los beneficios de la distinción están destinados a deteriorarse si el campo de producción, regido por la dialéctica de la pretensión, no ofreciera continuamente nuevos bienes o nuevas maneras de apropiárselos"2.

${ }^{2}$ El ensayista inglés Hirsch trasladó este tipo de análisis a los bienes posicionales para explicar la ferocidad de la competencia en el capitalismo, a raíz de la lucha desenfrenada por los bienes posicionales. 
Sin embargo, en materia vestimentaria el ajuste entre la oferta y la demanda no está en los condicionamientos de la producción, ni en el sometimiento de ésta a los gustos de los consumidores, sino en "la correspondencia de dos lógicas relativamente independientes: la lógica de los campos del consumo y de la producción" (Ibídem, p. 169). Es ahí donde el principio de la homología funcional y estructural hace que ambas lógicas sean concertadas de manera objetiva, por el hecho de que todos los campos especializados, como el del vestido, tienden a organizarse según el mismo criterio: según el volumen del capital poseído y según la antigüedad de la posesión. Por consiguiente, las incesantes transformaciones de la moda son producto por una parte del concierto objetivo, de las luchas internas en el campo de la producción que se organizan según la oposición entre lo antiguo y lo nuevo, lo caro y lo barato..., y por otra, de la lógica de las luchas internas en el campo de la clase dominante que enfrentan a los poseedores y a los pretendientes pretenciosos. Por lo tanto, no es casual que la búsqueda de la distinción no necesite presentarse y afirmarse como tal, ya que una educación burguesa basta para determinar los cambios más especiales en un momento dado del tiempo. Por el contrario, la pequeña burguesía de formación reciente hace demasiado esfuerzo, traicionando así su inseguridad, y desvalorizándose por la propia intención de distinción.

\section{LA MODA Y EL CAMBIO SOCIAL}

Frente a esta corriente principal de la sociología de la moda, que la interpreta como un mecanismo de competencia vertical entre las clases, existe otra interpretación, que cabe definir como la perspectiva de asociar a la moda con el cambio social y modernizador, en línea con la escuela funcionalista. Ello supone adentrarnos en las teorías de Blumer, Alberoni, Gil Calvo, Piñuel Raigada y Muñoz Carrión, entre otros. Dado que en una sociedad, como la actual, donde el cambio tecnológico es incesante y acelerado y en la que es igualmente constatable la permanencia de las formas sociales, es necesario hacer a los individuos miembros disponibles para aceptar la innovación permanente de sus capacidades y, al mismo tiempo, mantener la inmutabilidad de las relaciones que sostienen la cohesión social.

Blumer (1968: 155-157) fue el primero en identificar la moda como un regulador del cambio social, en un artículo en el que se exponen los nudos centrales de esta cuestión: ¿cuál es la naturaleza en que opera el proceso de la moda?; ¿quién es responsable de su acción?, y, por último, ¿qué papel desempeña en la sociedad?. En su opinión, el proceso de la moda se ajusta a este mundo cambiante a través de dos etapas muy importantes: la innovación y la selección. En la etapa de innovación, los nuevos modelos son presentados, pero cada uno intentará iniciar sus propias líneas hacia el futuro. De esta manera, los modelos apare- 
cen como rivales en su lucha por ser adoptados, iniciándose así un proceso de selección del cual nacerá una nueva moda.

No obstante, la función principal del proceso de la moda en la sociedad consiste en introducir formas sociales de control en un área de divergentes posibilidades, en cuanto produce una uniformidad al seleccionar uno entre muchos modelos, que llevará el signo de apropiado, impeliendo así a su adhesión. «La moda en una sociedad que cambia cumple la función de control social igual que la costumbre en una sociedad estática» (Ibídem, p. 156). Asimismo, facilita una transición ordenada del pasado al inmediato futuro; pues al presentar muchos modelos y someterlos a un proceso de competencia y selección, la moda ofrece un «continuo mecanismo de ajuste» (Ibídem) para un mundo cambiante, en el sentido de que libera las formas sociales de los lazos del pasado, pero mantiene una continuidad de desarrollo respecto a la moda precedente. Finalmente, la moda consigue "formar y nutrir los gustos comunes", al ofrecer una base para aproximarse al mundo, como lo indica la afinidad que se siente en relación con la moda vigente, en contraste con las pasadas.

Por su parte Gil Calvo (1985), analizando el fenómeno de la moda, pone de relieve que la juventud urbana es el colectivo que más recurre a la moda para adaptarse a esos entornos cambiantes, generando su propia moda juvenil, mientras está en la cola de espera para penetrar en el sistema productivo. Y también explica por qué las modas pueden trasmitir tanta información a los jóvenes al actuar como un regulador de la conducta.

Los jóvenes, para adaptarse a las variaciones del entorno, sólo pueden extraer la información a través de la comunicación primaria transmitida por la familia, la religión o las ideologías; o la secundaria, transmitida por la cultura de masas o las modas audiovisuales, y, la terciaria, que se extrae de la enseñanza, la ciencia o la tecnología. Si la comunicación primaria sólo puede transmitir información acerca de las variaciones que se producen entre el sistema productivo y el ambiente del que depende, y sólo es comunicable a quienes pertenezcan a esa comunidad de interés, los jóvenes, al no ser adultos, no necesitan cerrarse al exterior, sino abrirse, ya que la comunicación transmitida por la enseñanza y por la ciencia resulta bloqueada y nula; debido a su lentitud y rigidez no logra transmitir información utilizable para adaptarse a las cambiantes oportunidades vitales. En cambio, donde fracasa la enseñanza triunfa la moda, dada su permanente reconversión tecnológica, ya que varía y evoluciona como puede variar y evolucionar la estructura ocupacional. De esta forma, la gran proliferación de las modas difunde a bajo coste las variaciones del entorno para todo aquél que a ellas se conecte. De ahí, su absoluta vigencia y capacidad de regulación, ya que informa con mayor flexibilidad y riqueza de matices de los cambios del entorno; de ahí también que juegue un papel tan fundamental en la vida de los jóvenes antes de ingresar en el mundo adulto.

Llegados a este punto, hay que destacar las dimensiones relacionales de la 
comunicación visual de las modas, al permitir presentar los diferentes estilos juveniles como canales específicos a través de los cuales los jóvenes quedan informados, tanto de su situación respecto de los adultos, como de las diferentes relaciones que entre sí mantienen los distintos grupos sociales en que aparece dividido el sector joven de la sociedad industrializada ${ }^{3}$.

Al respecto Piñuel Raigada señala que la adopción de innovaciones marcadas por la moda la efectúan los sujetos persiguiendo psicológica, comunicativa y socialmente obtener imágenes corporales, referenciales y sociales de sí mismos. $\mathrm{Y}$, al examinar cómo construye el joven de hoy su identidad social, observa que ello sucede a partir de las interacciones comunicativas, especialmente en el interior de los grupos de pares o iguales aunque, en opinión de Avello y MuñozCarrión, se trata de una identidad que nada tiene que ver con la clase social a la que el joven pertenece ni con la ideología, sino que se construye para expresar la propia identidad sin más. Ahora bien, la interpretación de su propia identidad (sus gustos, sus sentimientos y su estilo) procede del consumo, ya que el joven actúa como un consumidor, y su interpretación se reconoce por los productos que consume, y son ellos los que le proporcionan la identidad y el beneficio del reconocimiento entre sus pares. Y, como buen personaje que es, sabe cambiar y renovar su imagen sin desfallecer y adaptarse dócilmente a los cambios que desde fuera le proponen.

Como consecuencia de esta nueva relación entre producción y consumo se ha desarrollado una nueva cultura que E. Morin define como de masas. La cultura de masas proporciona a la vida privada modelos de comportamiento en relación con los valores de consumo a través de la distribución de información, cuya misión es la de provocar la necesidad de nuevos bienes introducidos en el mercado.

En el contexto situacional de la juventud, el seguimiento de la rápida sucesión de las modas cobra una importancia de primera magnitud, ya que esa múltiple y veloz sucesión de hábitos conductuales es el específico instrumento de control social y vehículo de cambio de las sociedades modernas ${ }^{4}$, pues frente al retardado y lento ritmo de cambio social de las sociedades tradicionales, donde la conducta se rige por un conjunto escasamente dinámico de costumbres ancestrales, las sociedades modernas inauguran el vértigo de un superacelerado cambio colectivo. En tales condiciones, el seguimiento de la moda es la manera más adecuada de recibir información sobre los procesos de cambio. "Seguir la moda imitando a los famosos es el medio menos costoso de adaptar la propia conducta a la estructura social y al cambio social" (Gil Calvo, op.cit: 67).

\footnotetext{
${ }^{3}$ Sobre este punto Gil Calvo, Piñuel Raigada y Martín Serrano se decantan hacia la dimensión relacional de la comunicación de las modas vestimentarias.

${ }^{+}$Este es el argumento de Blumer.
} 


\section{LA CAPACIDAD SEDUCTORA DE LA MODA}

Finalmente, otra de las consideraciones en las que están de acuerdo tanto la sociología clásica como la sociología moderna respecto de la moda, es su puesto central en el cuadro de los fenómenos expresivos. Esta expresividad se refiere a la capacidad de iniciar y establecer relaciones sociales de tipo horizontal, haciendo posible que actores individuales o grupales situados en el mismo nivel de estratificación social contraigan vínculos comunicativos de naturaleza emocional que pueden variar desde el amor, la pasión, el deseo, la admiración, la seducción y la amistad, hasta el odio, el rencor, la envidia y la rivalidad. Esta perspectiva ha de ser adicionalmente admitida como complemento a las anteriores y ha sido fundamentalmente reconocida por Lipovetsky.

La mayoría de los estudios sobre la moda vestimentaria, como los de König, Flügel, Stoezel, Barthes o Squicciarino, han llamado la atención sobre cómo su fundamento instintivo está estrechamente relacionado con el comportamiento sexual, hecho que se menciona a propósito de la actitud ambivalente del hombre frente al vestido. El individuo, especialmente el del sexo femenino, se ve en el dilema de tener que elegir entre ofrecer y poner de relieve el cuerpo y salvaguardar el pudor, ya que entre las muchas cualidades que tiene el vestido, está la de su carácter alusivo, siendo posible que actúe como un mecanismo regulador a través del cual despertar o atenuar a voluntad el interés sexual. A esta cualidad del vestido, Barthes la definió como "la evidencia de lo interior" (Barthes, 1978: 201). Para los psicoanalistas, el énfasis que se pone en la propia imagen corporal se debe "al deseo de reforzar la atracción sexual y llamar la atención sobre los órganos genitales del cuerpo" (Flugel, 1964: 25). Y, desde el punto de vista de la sexualización general de la vida humana, se sostiene la tesis de que el origen de la moda, así como su desarrollo, se remonta a la necesidad de variación erótica hombre-mujer (Squicciarino, 1990: 157).

La función abiertamente sexual de las ropas es obvia. Tanto el diseñador que las crea, como el modisto que las vende, el moralista que las denuncia o el historiador del vestido, todos ellos concuerdan en que su propósito abierto y consciente es estimular la atracción sexual de los que la usan y estimular el interés de los admiradores del sexo opuesto y la envidia de sus rivales. Concretamente, en Lipovetsky (1990: 21-119) este carácter alusivo de la vestimenta adquiere carta de naturaleza como una función explícita de la moda. De hecho, identifica las relaciones asimétricas entre ambos sexos como el motor principal de la moda, y, de acuerdo con este criterio, establece tres períodos. En el primero, entre 13501750 , quien sigue la moda es el varón en lugar de la mujer. En el segundo, tras la caída del Antiguo Régimen, las tornas se invierten. El protagonismo seductor pasa a ser monopolizado por las mujeres. El tercer período, que se inicia en la segunda mitad del siglo XX, con la irrupción de los jóvenes en el sistema de la moda, no difiere del anterior, ya que sigue adoptando la misma lógica interna en 
términos de asimetría sexual. Todo esto confirma que donde se concentra en mayor medida esta función expresiva y seductora es en las relaciones de seducción y de conquista, especialmente en la tensión sexual y amorosa que opone a uno y otro género. De ahí, que las personas que siguen la moda, aunque no lo adviertan ni sean conscientes de ello, no lo hacen tanto para distinguirse del sexo opuesto, como para ser diferencialmente distinguidas por el sexo opuesto. Así, la moda es un medio retórico de expresión, que comunica asimétricamente a ambos géneros. Y en esto concuerda con la etología, en el sentido de que la moda es una impronta o display cultural, puesta al servicio de las paradas nupciales y los rituales de cortejo, tal como lo describen los etólogos (Wilson, 1980). De la misma forma que la percepción y el cortejo sexual a través de los estímulos estéticos están bastante difundidos en el mundo animal, este mismo fenómeno tiene una afinidad con la tendencia humana a seguir la moda.

Ahora bien, en las sociedades modernas, los rituales de cortejo amoroso se caracterizan porque las mujeres, en lugar de ser encerradas en casa al alcanzar la edad núbil, ven prolongarse su adolescencia en la que deben exhibirse y adornarse con sus mejores galas para resultar deseables. De este modo, la capacidad expresiva y seductora de la moda está puesta horizontalmente al servicio de la seducción y de la conquista, siendo ahí donde las mujeres la utilizan en mayor medida que los hombres como uno de los agentes propios de sus estrategias. Siguiendo la teoría del capital humano (Becker, 1983) se observa que, en los procesos de búsqueda de los mercados matrimoniales, se exige invertir en una serie de gastos de autorepresentación, esto es, en capital expresivo (moda belleza, marcas..) y en capital relacional (acudir a bares, discotecas...), con objeto de situarse mejor dentro del mercado matrimonial. De ahí, el interés que suelen tener las mujeres en invertir en capital expresivo. Al mismo tiempo, se puede observar que estas relaciones de nupcialidad, medidas por la moda, presentan también objetivos de movilidad social ascendente, esto es, la hipergamia femenina de emparejarse con machos de mayor prestigio o estatus.

Finalmente, señalar que esta capacidad expresiva y seductora de la moda ya fue reconocida de forma más o menos implícita por Simmel y más recientemente por Bourdieu (1991: 239-240). Concretamente, el sociólogo francés la reconoce cuando afirma que las características expresivas que cada cuerpo lleva consigo, constituye el fundamento más inmediato de las afinidades electivas, ya que no existe una prueba más indiscutible de las compatibilidades o incompatibilidades, que la que resulta del libre juego de la elección amorosa.

\section{LA VARIABILIDAD DEL VESTUARIO}

Finalizado el análisis teórico, el siguiente objetivo de este trabajo es analizar el modo en que cada una de las variables de control consideradas (sexo, estado 
civil, edad, situación laboral, nivel de estudios y categoría profesional) ejercen una influencia causal y explicativa sobre las variaciones del vestuario de los sujetos de la encuesta ${ }^{5}$.

\section{El efecto renta o capital humano}

Por efecto renta o capital humano se entiende los efectos causales atribuíbles a las variaciones del vestuario, según la ocupación, actividad y nivel de estudio de los entrevistados. En particular, se trata de analizar la influencia que sobre la composición del vestuario ejerce la carrera ocupacional a la que acceden los sujetos tras haber desarrollado su carrera educativa. Este efecto-renta es el más sobresaliente de todos, ya que, por una parte, es el que explica las mayores desigualdades en la composición del vestuario, dividiendo a los sujetos que lo configuran dentro de la lógica de la no moda (o traje de vestir) y los que lo configuran dentro de la lógica de la moda (ropa sport y deportiva); y, por otra parte, es el que explica las mayores reducciones en la configuración indumentaria, como también la desigualdad entre varones y mujeres, conforme se asciende de nivel de renta y, en consecuencia, de nivel cultural.

En primer lugar, en la tabla 1 se puede apreciar que la variable de la situación laboral tiene una influencia muy considerable. Concretamente, en la categoría de «activos o trabajadores» se observa una superioridad en «el grupo de prendas de vestir». Esto significa que los trabajadores que están integrados en el mundo del trabajo retribuido, componen fundamentalmente su vestimenta en función del desarrollo de su carrera profesional ${ }^{6}$. Por el contrario, los grupos que están

\footnotetext{
${ }^{5}$ Los datos proceden de la encuesta realizada por el CIS (estudio 2126) donde el corpus de datos estuvo integrado por 2.481 encuestas, dirigido a la población española de ambos sexos de 18 años y más que vive en municipios de más de 2.000 habitantes. La fecha de realización fue en enero de 1995. En la estructura del cuestionario se codificó una variable relativa a la configuración del vestuario con treinta y tres prendas. A su vez, éstas las hemos recodificado para su posterior análisis en «ropa de abrigo» (gabardinas, impermeables o prendas de lluvia, chaquetones, tres cuartos, trenkas, zamarras, pellizas y cazadoras); «ropa de vestir» (trajes de chaquetas de pantalón o falda, americanas, chaquetas, blazier, pantalones normales, camisas y blusas vestir); «ropa de sport» (pantalones vaqueros, mallas, pantalones cortos y bermudas, chaleco, camisas y blusas sport, jerseys y chaquetas de punto, polos, niquis, camisetas); «sólo de mujer» (faldas clásicas, vaqueras, de pantalón, minifalda/maxi falda, vestidos); «prendas deportivas» (chandals, sudaderas, camisetas, pantalones cortos, bañadores, calzado deportivo); «complementos» (sombreros, gorras, panuelos de cuello, bufandas, corbatas y pajaritas, cinturones, tirantes, guantes, bolsos); "pares de calzado» (calzado de vestir, o de sport).

${ }^{6} \mathrm{El}$ autor que ejemplifica el traje masculino como símbolo de promoción social es F. Alberoni (1976: 63-75).
} 
Tabla 1.

Número de prendas en uso por grupos de prendas, según situación laboral.

\begin{tabular}{|c|c|c|c|c|c|c|}
\hline Grupos prenda & Trabajador & Jubilado & Parado & Estudiante & $\begin{array}{c}\text { Situación } \\
\text { Laboral }\end{array}$ & $\begin{array}{l}\text { Total/ } \\
\text { Media }\end{array}$ \\
\hline De abrigo & 4,21 & 4,28 & 3,77 & 4,39 & 3,45 & 3,86 \\
\hline De vestir & 13,71 & 10,65 & 10,61 & 8,82 & 8,84 & 11,31 \\
\hline De sport & 18,99 & 9,00 & 18,38 & 25,37 & 11,90 & 16,31 \\
\hline Deportivas & 10,26 & 2,83 & 9,71 & 15,42 & 4,36 & 8,15 \\
\hline Sólo para mujeres & 8,07 & 7,98 & 7,54 & 6,79 & 7,90 & 7,82 \\
\hline Complementos & 10,47 & 8,71 & 8,72 & 8,44 & 9,29 & 9,50 \\
\hline Calzado & 5,18 & 4,11 & 4,61 & 4,57 & 4,96 & 4,81 \\
\hline
\end{tabular}

fuera del mercado laboral, como los jubilados, pensionistas, parados y amas de casa, son los que registran las medias más bajas, tanto por grupos como por clases de prendas (salvo en el caso de la falda clásica y los vestidos). Así, se puede decir que entre la categoría de los no activos se observa un guardarropa más pobre y menos variado que el de los activos. Y es que en el caso de los jubilados y pensionistas, como para los parados de larga duración, el abandono de la carrera profesional trae consigo un cambio en la propia composición de su guardarropa, como el abandono progresivo del traje «clásico», y todas las prendas que este tipo de vestimenta lleva consigo.

Y en lo que respecta «al grupo de prendas sólo para la mujer», la categoría de activas muestra también una superioridad en comparación con la media total, confirmándose que las mujeres que desarrollan una carrera profesional muestran un mayor volumen de prendas, tanto por «grupos de prendas» como por «clases de prendas». Por el contrario, para el caso de las «amas de casas», la no integración en el sistema de trabajo remunerado condiciona la variabilidad del vestuario, pudiéndose apreciar las medias muy bajas para el conjunto de los seis «grupos de prendas» como por el número de prendas individualmente.

Sin embargo, la categoría de estudiantes registra un menor volumen de «prendas sólo para la mujer». Ésto no es extraño, ya que este grupo suele estar integrado por individuos entre 18-25 años, que es la etapa en la que el sistema vestimentario es más simétrico. Asimismo, donde más se manifiesta una superioridad es en el grupo de prendas de «sport» y «deportiva», ya que componen su vestuario dentro la lógica de la moda; esto es, una ropa cómoda, práctica y muy funcional, como claros exponentes de la cultura del individualismo contemporáneo, donde está ausente la lógica de la moda «clásica». Sin embargo, la incorporación al mundo laboral produce variaciones en la composición de su vestuario, en función de lo que su carrera les exija. 
Esta evidente superioridad en la composición del guardarropa de las personas activas o trabajadoras, no sólo se debe al efecto de la situación laboral, sino que también se manifiesta a través del propio nivel de estudios del entrevistado, considerando que las personas menos escolarizadas son las que suelen caer con más frecuencia en el desempleo. Por ello, la variable «nivel de estudios» explica muy bien la riqueza y la variedad en la composición del vestuario de los españoles.

Si bien es cierto que seguir estudios, por encima de cualquier consideración, es la antesala de la carrera ocupacional, de lo que aquí se trata es de tener en cuenta la teoría del capital humano, así como poner de manifiesto que existe una clara continuidad explicativa entre la influencia positiva que ejerce el nivel de estudios y la no menos positiva que ejerce la categoría profesional a la hora de configurar su vestuario.

En la actualidad, la función de distinción de la moda depende de dos factores básicos: de una parte, el tiempo (que constituye el coste de la transacción, tanto por el tiempo invertido en recabar la información pertinente en el mercado de la moda, como por el tiempo consumido en su adquisición); y de otra, el volumen de capital (económico, cultural y social) que determina el beneficio de la distinción. Así, a mayores ingresos y más nivel cultural, mayor será el beneficio asignado por los consumidores a la moda.

Por una parte, la teoría del capital humano (Becker, 1983 y 1987) explica cómo en ese proceso de búsqueda de información en el mercado de la moda se producen unos gastos necesarios para indagar y examinar las distintas novedades que oferta dicho mercado, como, por ejemplo, el tiempo en recabar tal información. Este hecho trae consigo «un coste oportunidad», esto es, una renuncia a invertir en la mejora del capital instrumental en beneficio del capital expresivo, o en palabras de Goffman, en una mejora de las «formas de autorepresentación» (Goffman, 1981). Y, por otra, la teoría de capital cultural (Bordieu, 1991; Bordieu y Passeron, 1981) señala que otro de los factores claves para estar informados dentro del mercado simbólico de la moda reside en las diferencias de socialización que poseen determinados grupos sociales (clase media y burguesa) y que se reproduce a través de la escuela, lo que en realidad es una selección previamente decidida por el origen social. Y es que el «capital cultural» hace especial referencia al uso que se puede dar a determinadas posesiones simbólicas que un individuo tiene.

Del contenido de los datos de la tabla 2 puede observarse que los sujetos con estudios superiores son los que presentan un vestuario más rico y variado con dos lógicas distintas: la lógica de la moda (traje sport y deportiva) y la lógica de la no moda (traje de vestir). Esto es debido no sólo a que poseen un mayor nivel de estudios, sino a la propia ocupación, que les exige un tipo determinado de vestimenta. En efecto, el desempeño de un trabajo requiere no sólo un enriquecimiento intelectual, sino también una buena forma de autopresentarse y así traslucir el propio gusto que el capital cultural procura. 
Tabla 2.

Número de prendas en uso por grupos de prendas, según nivel de estudios.

\begin{tabular}{lcccrr}
\hline Grupos prenda & $\begin{array}{c}\text { Menos de } \\
\text { Primarios }\end{array}$ & Primarios & Bachiller & Superior & Total \\
\hline De abrigo & 2,55 & 3,67 & 4,60 & 4,95 & 3,88 \\
De vestir & 7,79 & 10,83 & 12,78 & 15,06 & 11,37 \\
De sport & 7,09 & 14,59 & 23,28 & 22,74 & 16,46 \\
Deportivas & 2,40 & 6,94 & 13,96 & 10,94 & 8,19 \\
Sólo para mujeres & 6,78 & 7,79 & 8,22 & 8,68 & 7,82 \\
Complementos & 5,77 & 8,89 & 10,82 & 13,69 & 9,54 \\
Calzado & 3,72 & 4,55 & 5,43 & 6,23 & 4,83 \\
\hline
\end{tabular}

En lo que respecta al nivel de bachiller, se manifiesta una superioridad en el caso del «grupo de prendas deportivas». Este hecho no es extraño, dado que este nivel suele estar integrado preferentemente por la categoría de estudiantes. Por el contrario, las medias más bajas se aprecian entre los entrevistados con menores niveles de estudios respectivamente: menos de primarios y primarios. Esto indica que el capital cultural ejerce una influencia muy considerable a la hora de configurar la vestimenta. Y por lo que se refiere al grupo de prendas «sólo para las mujeres», se observa que, a medida que aumenta el nivel de estudios de la entrevistada, aumenta el número de prendas que tiene en su guardarropa, e incluso, integran prendas de origen masculino como el traje de chaqueta de falda o pantalón. Asimismo, cabe señalar que el «grupo de complementos» está en relación directa con el nivel de estudios, dado que, a medida que aumenta el nivel de estudios de los entrevistados, mayor es el número de complementos en su guardarropa.

Si tan significativa resulta la influencia del inicio, desempeño y finalización de la carrera ocupacional, bueno es conocer la influencia que ejercen las distintas ocupaciones sobre la propia variabilidad del vestuario de los españoles. Desde un punto de vista general, hay que destacar que para las tres categorías profesionales se observa una superioridad de la vestimenta «sport» como expresión de la cultura del individualismo narcisista. En las sociedades modernas, el consumo de moda ha dejado de ser una actividad regulada por la búsqueda del reconocimiento social, para desplegarse hacia el bienestar, la funcionalidad y el placer de sí mismo ${ }^{7}$. No obstante, este predominio de la vestimenta «sport» se manifiesta de forma proporcional a la propia categoría profesional; a mayor categoría profesional corresponde una mayor superioridad de este grupo de prendas.

7 Sobre el desarrollo del individualismo narcisista en el ámbito de la moda. Véase, Lipovetsky (1990: 119-171) y Morace (1988: 127-138). 
De los datos de la tabla 3, hay que destacar que el efecto renta distribuye de manera decreciente el número de prendas en su guardarropa, confirmándose la relación o interdependencia entre la propia estructura socioprofesional y la estructura de la variabilidad del número de prendas que tienen en su vestuario, componiendo una curva en forma de campana con una mínima variedad en los extremos del arco (agricultores y obreros sin cualificar), frente a la máxima variedad en la clave de la bóveda del arco (directivos, empresarios, profesionales, cuadros técnicos), y los integrantes de la clase media, en la parte media de esa misma campana, con las características de esos valores medios.

Para concluir este apartado hay que subrayar que en las categorías superiores de estas variables (sujetos que son activos, que desempeñan una ocupación como profesionales por cuenta propia o ajena y que poseen un título superior) es donde aparecen los vestuarios más ricos y variados, tanto por cantidad de prendas como por grupos de prendas. Y, del mismo modo, en esas categorías es donde aparece la máxima igualdad entre los géneros, lo que viene a significar los valores más elevados de superioridad femenina en actividades cultas masculinas, especialmente a través de los trajes de chaqueta. Al parecer, las mujeres que compiten profesionalmente en pie de igualdad con los hombres, adoptan como traje de trabajo «el traje de chaqueta de falda o pantalón» como el traje de éxito. Algunas investigaciones realizadas en España se han referido a este fenómeno. Concretamente, la socióloga María Antonia García de León mantiene que algunas pistas de la androginización forzada de la mujer, como nueva forma de aceptación de la dominación masculina, se pueden encontrar en el uso sistemático, por parte de las mujeres profesionales, de trajes oscuros, americana sobria y la eliminación radical de lo que podríamos llamar estilo femenino (García León, 1995: 60-66).

El poder explicativo del efecto-renta sobre la configuración del vestuario es doble. Por una parte, el nivel de renta explica el acceso a los recursos materiales

Tabla 3.

Número de prendas en uso por grupos de prendas, según categoría profesional.

\begin{tabular}{lrrrr}
\hline Grupos prenda & Alta & Media & Media-baja & Total \\
\hline De abrigo & 4,98 & 4,13 & 3,40 & 3,85 \\
De vestir & 14,25 & 12,49 & 9,89 & 11,31 \\
De sport & 16,71 & 14,01 & 11,25 & 12,88 \\
Deportivas & 11,22 & 9,58 & 6,51 & 8,06 \\
Sólo para mujeres & 8,68 & 8,26 & 7,21 & 7,79 \\
Complementos & 13,73 & 10,81 & 7,64 & 9,49 \\
Calzado & 6,05 & 5,17 & 4,25 & 4,79 \\
\hline
\end{tabular}


necesarios para poder adquirir un vestuario más complejo. Por otra, el desempeño de una determinada ocupación predispone a los sujetos hacia una composición determinada que explicita su competencia expresiva, es decir, su «gusto», que expresa su legitimidad habitual en llevar determinadas prendas. Y es así como se explica que la composición del vestuario de las mujeres activas, sobre todo si disponen de una ocupación remunerada, sea más rico, variado y moderno que el de las inactivas. De ahí que se haya podido apreciar que el desarrollo o el abandono de la carrera ocupacional ejerce positiva o negativamente una influencia sobre la variabilidad del vestuario de los españoles.

\section{EL EFECTO-EDAD SOBRE LA VARIABILIDAD DEL VESTUARIO}

Tras el efecto-renta, es el efecto-edad o ciclo de vida el que mejor explica la variabilidad del vestuario. De hecho, la edad es uno de los factores más discriminantes a la hora de configurar el guardarropa. Si bien es cierto que la edad es una de las variables explicativas más influyentes, como veremos a continuación, ésta no es una variable independiente, sino que, por el contrario, podemos considerarla como una variable interviniente, encargada de transmitir los efectos que las auténticas variables independientes (como el sexo, estado civil y la actividad ocupacional) ejercen sobre la variabilidad vestimentaria.

Ahora bien, puesto que la mayor parte de los comportamientos humanos son actividades procesuales, que se desarrollan a lo largo de prolongados períodos de tiempo, es de suponer que según cuál sea la edad que se tenga, así será la configuración de su vestuario, puesto que al cambiar de edad se cambia de posición social; es decir, se pasa de soltero a casado, de estudiante a empleado, o de activo a parado. Por consiguiente, las sucesivas posiciones que uno va ocupando a lo largo de las distintas etapas que jalonan el curso de la carrera educativa, familiar y ocupacional serán las que determinen institucionalmente la variabilidad del vestuario de los sujetos que las ocupan, dado que éste variará con la edad y en función del punto de desarrollo en que se hallen esas tres carreras. Sin embargo, este principio, que es de general aplicación para todos los sujetos, es sustancialmente distinto según se trate de varones o mujeres, ya que las tres carreras resultan contrapuestas según el género.

En nuestra sociedad, el curso de vida masculino está jerárquicamente centralizado por la carrera ocupacional, a cuyo logro maximizador resultan supeditadas las otras dos carreras (educativa y familiar). En cambio, en el caso de las mujeres no sucede lo mismo, aunque la carrera ocupacional femenina ha cobrado recientemente una prioridad que antes no tenía. En cualquier caso, el curso de la vida femenina continúa estando mayoritariamente centralizado por la carrera familiar, a cuyo mayor éxito resultan supeditadas las otras carreras (educativa y ocupacional). Esta disparidad de los criterios articuladores de los respectivos 
Tabla 4.

Número de prendas en uso por grupos de prendas, según edad.

\begin{tabular}{lrrrrrr}
\hline Grupos prenda & $\begin{array}{c}18-25 \\
\text { años }\end{array}$ & $\begin{array}{r}26-35 \\
\text { años }\end{array}$ & $\begin{array}{c}36-45 \\
\text { años }\end{array}$ & $\begin{array}{r}46-55 \\
\text { años }\end{array}$ & $\begin{array}{r}+56 \\
\text { años }\end{array}$ & Total/Media \\
\hline De abrigo & 4,12 & 4,32 & 4,01 & 3,83 & 3,33 & 3,86 \\
De vestir & 8,90 & 13,19 & 13,21 & 12,29 & 10,21 & 11,34 \\
De sport & 24,16 & 21,59 & 27,66 & 13,20 & 8,85 & 16,40 \\
Deportivas & 14,54 & 11,72 & 9,03 & 5,41 & 3,44 & 8,19 \\
Sólo para mujeres & 6,43 & 8,17 & 8,05 & 8,57 & 7,94 & 7,82 \\
Complementos & 7,85 & 10,96 & 10,49 & 10,30 & 8,70 & 9,52 \\
Calzado & 4,36 & 5,72 & 5,15 & 4,93 & 4,24 & 4,81 \\
\hline
\end{tabular}

cursos de vida, continúa determinando la desigualdad entre varones y mujeres, incluyendo la desigualdad a la hora de configurar su vestuario. Concretamente, este principio del doble ciclo vital es el que mejor explica la variación del guardarropa, tanto debido a la edad, como al género y al propio estado civil.

A la vista del contenido de la tabla 4 , se pueden apreciar grandes diferencias entre los distintos grupos de prendas según la edad del entrevistado. a) En lo que respecta al grupo de edad entre 18 y 25 años se observa una superioridad muy por encima de la media total, tanto en el grupo de prendas «sport» como «deportivas», configurando su vestuario dentro de la lógica de lo que se entiende por moda ${ }^{8}$, donde las innovaciones son más rápidas y novedosas. Este grupo de edad registra, además, las medias más bajas en relación con el grupo «de prendas de vestir», así como en el «grupo de prendas sólo para la mujer». Ésto se explica porque los jóvenes, al no haber contraído responsabilidades familiares ni profesionales, no tienen la necesidad de configurar su vestimenta en el sentido del traje «clásico». Es más, los jóvenes son el colectivo que recurre más a la moda generando su propia «moda juvenil», mientras están en la «cola de espera» hasta penetrar en el mundo adulto". Otra justificación es que en la etapa de la juventud (y para ambos géneros) las diferencias vestimentarias son menores debido a que éste es el momento del ciclo de la vida en que el sistema de la moda es más simétrico, para hacerse más asimétrico a medida que uno avanza en edad. Esta

\footnotetext{
${ }^{8}$ Para una aproximación sociológica al concepto de moda en sentido estricto, véase el diccionario de R. Reyes (1988) y el trabajo de M.A. Descamps (1986).

${ }^{9}$ Gil Calvo (1985), presenta toda la trayectoria socializadora de la juventud urbana desde la infancia hasta la integración plena en la estructura ocupacional.
} 
misma tendencia se reproduce en el grupo de los «complementos», dado que dentro del vestuario, éstos son los encargados de evidenciar las diferencias de género entre los sexos, como es el caso de bolsos y zapatos de tacón para las mujeres o las corbatas para los varones. Esto se debe a que los jóvenes ${ }^{10}$ no tienen cargas familiares, ni carrera ocupacional que desempeñar. Así, el vestuario juvenil resulta monótono y redundante por el tipo de prendas que lo configuran, fundamentalmente «pantalones vaqueros», «polos», «niquis» $\mathrm{y}$ «camisetas». De ahí que la simetría en el guardarropa entre chicos y chicas es casi total tanto en cantidad como en variedad.

b) Sin embargo, partiendo de esas posiciones iniciales, cada vez más simétricas, en seguida se produce la divergencia cuando se avanza en edad. La razón de esto reside en el calendario nupcial femenino. El cambio de estatus (casarse, meterse en casa) implica un cambio en la propia configuración del vestuario tal como expusimos anteriormente. A su vez, esta discontinuidad debe asociarse con el desarrollo de la carrera familiar que deben soportar las mujeres, ya que es lo que les lleva a configurar su vestuario hacia una claro predominio de ropa exclusiva para la mujer. Es más, esta carga familiar no es soportada en igual medida por los varones, pues la carrera ocupacional les exige configurar su vestuario hacia el denominado «traje clásico». Esto explica la asimetría vestimentaria, ya que empieza a producirse entre los géneros" e irá reforzándose por el fenómeno de la sobrecarga familiar para las mujeres y el desarrollo ocupacional entre los varones. Y es aquí, en el desigual reparto entre los géneros de la carga familiar o la carrera ocupacional, donde cabe reconocer la clave explicativa de la variabilidad del vestuario de las mujeres o varones adultos, cuyo punto de inflexión se centra en el grupo de edad entre 26 y 36 años, cuando comienza el desarrollo de la carrera familiar/ocupacional.

c) En las etapas siguientes, la composición del vestuario se articula en el mismo sentido que la anterior, si bien puede apreciarse un menor volumen de prendas en su guardarropa. Sin embargo, la dualidad del vestuario entre ropa de vestir y ropa de sport se mantiene hasta ir descendiendo de forma paulatina en el grupo de edad de más de 56 años. En este grupo de edad, la única superioridad tan sólo se manifiesta en la ropa de «abrigo».

\footnotetext{
${ }^{10}$ Dentro de esta argumentación, «son jóvenes aquellos individuos que habiendo madurado fisiológicamente, todavía no poseen ocupación productiva estable, cónyuge y domicilio propio ni descendencia». Véase, Gil Calvo (1985: 13-32) y Piñuel Raigada (1994).

"Sobre el origen y evolución del sistema de la moda desde el punto de vista de la asimetría de los géneros, véase Lipovetsky (1990) y Gil Calvo (1991).
} 


\section{El efecto-rol o segregación femenina}

El calendario del curso de vida determina que, una vez finalizada la carrera educativa, debe comenzar la carrera ocupacional y después la carrera familiar (primeras nupcias, nacimientos y crianza de bebés...), apareciendo drásticos efectos sobre el vestuario. Inmediatamente, se reduce de raíz el volumen de tiempo disponible para invertir en capital expresivo ${ }^{12}$ al recortar el presupuesto destinado para el vestuario, ya que hay que permanecer en casa ocupándose de las responsabilidades familiares.

De esta manera, el efecto-rol (o segregación femenina), tercer efecto que se va a considerar a continuación, no es más que una de las dimensiones del efectoedad, cuyos cambios determinan el actuar diferencialmente en cada etapa del ciclo vital. Por efecto-rol debe entenderse la variación o desigualdad en la composición del vestuario, atribuible a la complementariedad de los roles sexistas que están asimétricamente contrapuestos. Por mucho que haya cambiado el status femenino en la sociedad capitalista desarrollada, subsisten determinadas prendas exclusivas para la mujer y prohibidas para el hombre, $\mathrm{y}$ tan sólo son explicables como consecuencia de la inercia histórica. La representación de las diferencias de género ha resistido mucho más que las de clase. De esta forma se perpetúa un proceso de diferenciación ostensible de los sexos a través de esos signos exclusivamente femeninos (vestidos, las faldas, medias y calzado) y donde más se manifiesta es en la complementariedad de los roles sexistas en que se basa la familia occidental actual ${ }^{13}$.

De la lectura de la tabla 5 se desprende una clara «superioridad masculina» en el grupo de las prendas «de vestir» $\mathrm{y}$ «deportivas». Dicha «superioridad masculina» no es extraña, dado que las prendas que la integran componen la vestimenta masculina desde del siglo XIX, como tampoco es de extrañar la superioridad de las prendas deportivas, cuando dicha práctica estuvo siempre adscrita a los varones.

\footnotetext{
${ }^{12}$ Siguiendo la teoría del capital humano en invertir en «capital expresivo», puede verse Becker (1987: 287). Una visión crítica sobre la inversión en «capital expresivo» desde un punto vista feminista es la obra de Wolf (1991).

${ }^{13}$ Parsons (1960) propone para la sociología de la familia la tesis de la diferenciación y especialización funcional de los roles sexuales como un mecanismos de ajuste del sistema familiar y el sistema laboral en la sociedad industrial. Parsons enfatiza las diferencias biológicas y psicológicas entre los sexos, y al definir lo femenino y lo masculino como dos categorías opuestas, establece la separación entre el trabajo, la vida, la familia privada y la vida pública, y ubica diferencial-mente a los hombres y mujeres en la estructura social. La complementariedad de los roles femeninos y masculinos es la base sobre la que se asienta la estabilidad personal, familiar y social.
} 
Tabla 5.

Número de prendas en uso por grupos de prendas, según sexo.

\begin{tabular}{lrrr}
\hline Grupos prenda & Hombre & Mujer & Media/Total \\
\hline De abrigo & 3,8 & 3,8 & 3,8 \\
De vestir & 13,4 & 9,4 & 11,3 \\
De sport & 17,7 & 15,2 & 16,4 \\
Deportivas & 9,7 & 6,7 & 8,1 \\
Complementos & 8,8 & 10,1 & 9,5 \\
Calzado & 4,4 & 5,1 & 4,8 \\
\hline
\end{tabular}

$\mathrm{Al}$ proceder al análisis de varianza para cada tipo de prenda, se observa una clara superioridad masculina en las prendas de origen masculino, como es el pantalón, la americana, la chaqueta o blazier. Sin embargo, se manifiesta una superioridad femenina en el denominado «traje clásico», esto es, en el «trajechaqueta pantalón o falda». Esta superioridad femenina en dicha prenda viene a traslucir la masculinización del vestuario femenino; también se puede considerar que la incorporación de la mujer al mundo laboral viene a manifestar un cambio en su vestimenta y la consiguiente modificación en la composición de su vestuario $^{14}$.

En el «grupo de los complementos», también se observa una clara «superioridad femenina», excepto para el caso concreto de las «corbatas y pajaritas», complementos por excelencia de uso masculino. Esta manifiesta superioridad femenina en los complementos, evidencia que el sistema de la moda actual, en lo que respecta a las diferencias por género, se refleja en los pequeños detalles, como los bolsos.

Por otra parte, no debe extrañar que el cambio de estar soltero, libre por tanto de responsabilidades familiares, y de desarrollar una carrera profesional, determine que configuren su vestuario de acuerdo a su situación personal; esto es, hacia la «ropa de sport» y «la ropa deportiva». Por el contrario, los casados la configuran hacia el «grupo de prendas de vestir» para el desempeño de su carrera familiar. El efecto-rol se aprecia en el estado civil, sobre todo en el «grupo de prendas sólo para la mujer» y en «los complementos», con una sutil superioridad entre las mujeres casadas para el desempeño de su rol de esposa y madre.

\footnotetext{
${ }^{14}$ Para ilustrar este síntoma externo de la aculturación interna hacia el modelo masculino que han experimentado muchas mujeres políticas y profesionales españolas en general puede verse, por ejemplo, la entrevista de: «Rosa Conde, El look del Gobierno», Futuro, num. 67, abril 1992.
} 
Tabla 6.

Número de prendas en uso por grupos de prendas, según estado civil.

\begin{tabular}{lrrrr}
\hline Grupos prenda & Solteros & Casados & Viudos & Media/Total \\
\hline De abrigo & 4,26 & 3,75 & 3,22 & 3,86 \\
De vestir & 10,48 & 12,07 & 8,51 & 9,53 \\
De sport & 22,37 & 14,36 & 8,56 & 16,41 \\
Deportivas & 12,70 & 6,61 & 2,48 & 8,17 \\
Sólo mujeres & 7,54 & 7,86 & 8,28 & 7,82 \\
Complementos & 9,13 & 9,78 & 8,71 & 9,51 \\
Calzado & 4,80 & 4,85 & 4,34 & 4,80 \\
\hline
\end{tabular}

De la interpretación explicativa de los resultados obtenidos, según el sexo del entrevistado, se desprende lo siguiente:

a) El mundo de la moda sigue organizado por una disimetría estructural. Las mujeres pueden permitirse llevarlo casi todo e incorporar a su guardarropa prendas de origen masculino. Por el contrario, a los hombres les está vedado ciertos códigos femeninos. En ningún caso pueden llevar vestidos o faldas, ya que son patrimonio de lo femenino. Así, la antinomia entre lo masculino y lo femenino sigue vigente como la gran renuncia masculina del siglo XIX de la que hablaba Flugel (1964).

b) Una menor austeridad en la vestimenta masculina y más signos de origen masculino en el guardarropa de las mujeres, no autorizan a diagnosticar la uniformidad de la moda y la desaparición en mayor o menor plazo de las modas por sexos.

c) La homogeneización de la moda por sexo, sólo se da desde un punto de vista superficial. En realidad, el sistema de la moda no deja de producir signos diferenciales, a veces menores, pero no superfluos en un sistema en que «las insignificancias lo hacen todo». Así, determinados artículos son los encargados de manifestar la asimetría de las apariencias.

\section{CONCLUSIONES}

Este trabajo ha querido ser una contribución a la superación del estudio de Kroeber sobre la variabilidad de la moda. Una de las críticas que se le hacen a su interesantísima investigación es el no haber considerado los factores capaces de influir en el curso de la moda, como los de índole económico o la participación de la mujer en el trabajo. A este respecto, hemos constatado, en primer lugar, que una de las mayores desigualdades vestimentarias se produce principalmente por «el efecto renta o capital humano». Dicho efecto divide a los sujetos que configuran su vestimenta dentro de la lógica de la no-moda (o traje-burgués) y la 
lógica de la moda (ropa-sport y deportiva). Asimismo se ha comprobado que los vestuarios más ricos y variados aparecen en los sujetos activos, que desempeñan una ocupación como profesionales por cuenta propia o ajena y que poseen un titulo superior. En segundo lugar, hemos constatado que la edad es otro de los factores más discriminantes debido a las sucesivas posiciones que los individuos van ocupando a lo largo de las distintas etapas de la vida (carrera educativa, familiar y ocupacional), determinando institucionalmente la variabilidad del vestuario de los sujetos que las ocupan. De ahí que la juventud carente de responsabilidades (familiares y ocupacionales) configure su vestuario a través de la lógica de la moda. En tercer lugar, la complementariedad de los roles sexistas determina la variación en la composición del vestuario, pues por mucho que haya cambiado el estatus femenino en las sociedades capitalistas, subsisten determinadas prendas exclusivas para la mujer y prohibidas para el hombre, que sólo son explicables por el propio sistema de género. Y, por último, cabe destacar que en todas las categorías de las variables se muestra la tendencia al abandono de las llamadas «prendas grandes» (abrigos, gabardinas) y el auge de las «prendas pequeñas», como la ropa sport.

\section{BIBLIOGRAFÍA}

ALBERONI, F. (1976), «Observaciones Sociológicas Sobre el Traje Masculino», Psicología del Vesti; pp. 63-75, Barcelona, Ed. Lumen.

AVELLO, J. y A. MUÑOZ-CARRIÓN (1989), «Cultura juvenil: la Comunicación Desamparada», Comunicación y Lenguaje Juvenil, pp. 23-54, Madrid, Ed. Fundamentos.

BARTHES, R. (1978), El sistema de la moda, pp. 201, Barcelona, Ed. Gustavo Gili.

BLUMER, H. (1968), "La Moda", Enciclopedia Internacional de las Ciencias Sociales, pp. 155157, Madrid, Ed. Aguilar.

BAUDRILLARD, J. (1974), La economía política del signo, p. 28, Madrid, Ed. Siglo XXI.

(1974), La Sociedad de Consumo: Sus Mitos y Sus Estructuras, Barcelona, Ed. Plaza \& Jané.

BECKER, G. (1983), El Capital humano, Madrid, Ed. Alianza.

(1987), Tratado sobre la familia, Madrid, Ed. Alianza.

BEJAR, H. (1993), La Cultura del Yo, Madrid, Ed. Alianza.

BOURDIEU, P. (1991), La Distinción. Criterio y Bases Sociales del Gusto, Madrid, Ed. Taurus.

(1984), «Haute Costure et Haute Culture», Questions de Sociologie, París, Ed. Minuit. 
BOURDIEU, P. y PASSERON (1981), La reproducción, Barcelona, Ed. Laia.

CABRILLO, F. y M. CACHAFEIRO (1993), «Estrategias Nupciales», Estrategias Familiares, Madrid, Ed. Alianza.

DESCAMPS, M.A. (1986), Psicosociología de la Moda, México, Ed. Fondo de Cultura Económica

FLUGEL, C.J. (1964), Psicología de la moda, Buenos Aires, Ed. Paidós.

(1964), Psicología del vestido, p. 25, Buenos Aires, Ed. Paidós.

GARCÍA DE LEÓN, M.A. (1995), «El quid de las estrategias femeninas», Claves de la Razón Práctica, núm. 50, pp.60-66.

GIL CALVO, E. (1991), «Moda e hipergamia: mercado matrimonial y estrategias de seducción», $L a$ Mujer Cuarteada, pp. 3160, Barcelona, Ed. Anagrama.

(1985), Los depredadores audiovisuales: juventud urbana y cultura de masas, Madrid, Ed. Tecnos.

(1992), La era de las lectoras: el cambio cultural de las mujeres españolas, Madrid, Ed. Instituto de la mujer.

GOFFMAN, E. (1981), La representación del individuo en la vida cotidiana, Buenos Aires, Ed. Amorrortu.

KROEBER, A.L. (1948), «On the Principle of Order in Civilitation as Exemplefield by Changes of Fashion», Antropology, pp. 329-336, New York, Ed. Harcourt Brace.

KROEBER. A.L y J. RICHARDSON (1940), «Three Centuries Woman`s Dress Fashions», Antropology Rec., vol.5, n², pp.111-154, University of California.

LASCH, C. (1981), La Cultura del Narcisismo, Madrid, Ed. Alianza.

LIPOVETSKY, G. (1986), La era del vacío, Barcelona, Ed. Anagrama.

(1990), El Imperio de lo Efímero. La moda y su destino en las sociedades modernas, pp. 21119, Barcelona, Ed. Anagrama."

(1993), «La era de look. La balcanización de la moda: libertad ansiedad de apariencias», Madrid, El País (jueves 8 de noviembre de 1993).

MARTÍNEZ BARREIRO, A. (1996), "Elementos para una teoría social de la moda", Sociológica, núm.1, pp. 97-124

(1998a), Mirar y hacerse mirar: La moda en las sociedades modernas, Madrid, Tecnos.

(1998b), Hacia una nueva cultura de la moda, La Coruña, Ed. Universidad de la Coruña. 
(1998c), “La moda en las sociedades avanzadas", Papers, núm.54, pp. 129-137.

MORACE, F. (1988), «Tendencias del comportamiento de la moda en Italia», pp. 127-138, Sevilla, Universidad Internacionål Menéndez Pelayo.

(1993), Contratendencias, Madrid, Ed. Celeste.

PIÑUEL RAIGADA, J.L. (1994), «La moda o el aprendizaje de la integración por el cambio», REIS, núm. 57, pp. 227-244.

SIMMEL. G. (1988), Sobre la aventura: ensayos filosóficos, pp. 28-29, Barcelona. Ed. Península.

SPENCER, H. (1974), «Principios de sociología», Buenos Aires, Ed. Revista de Occidente.

SQUICCIARINO, N. (1990), El vestido Habla: consideraciones psico-sociológicas sobre la indumentaria, p. 157, Madrid, Ed.Cátedra.

VEBELEN, T. (1974), Teoría de la Clase ociosa, México, Ed. Fondo de Cultura Económica.

WILSON, E. (1980), Sobre la Naturaleza Humana, México, Ed. Fondo de Cultura Económica.

WOLF, N. (1991), El mito de la belleza, Barcelona, Ed. Emecé Editores.

YONNET, P. (1998), Juegos, Modas y Masas, pp. 233-239, Barcelona, Ed. Gedisa.

SUMMARY. This work has two well different part. In the firts section, we analyse the principal theoretical contribution, about fashion that have been developed from the end of the 19th century until nowadays. Therefore, this work intends to be a contribution whose aim is to contrast and to integrate theories in explaining the fashion phenomenon. And, in the second section, we analyse the way in which every independent variable (sex, age, instruction, social, status...) has causal influence on changes in the Spanish people dress. Finally, we conclude that the effect of the rent or human capital, age, vital cycle and rol o femenine segregation, are the most important causes that determine changes in dress among Spanish people.

E-mail: anamb@udc.es 